\title{
Parallel search engine optimisation and pay-per-click campaigns: A comparison of cost per acquisition
}

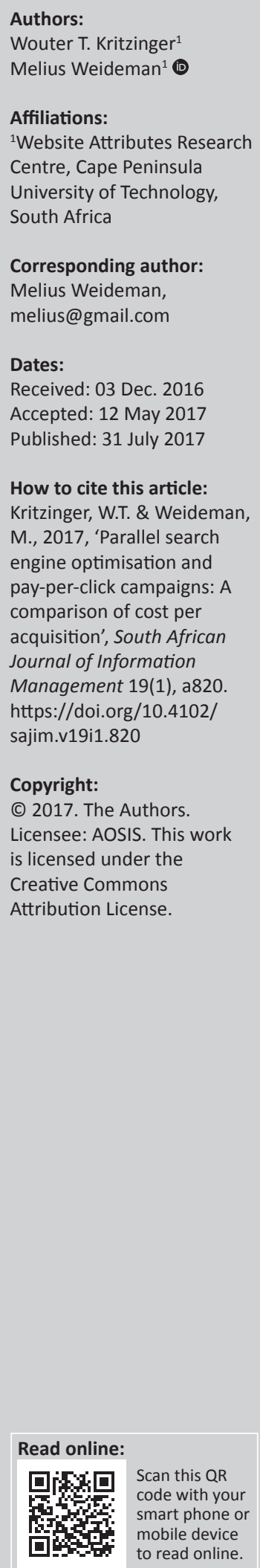

Background: It is imperative that commercial websites should rank highly in search engine result pages because these provide the main entry point to paying customers. There are two main methods to achieve high rankings: search engine optimisation (SEO) and pay-per-click (PPC) systems. Both require a financial investment - SEO mainly at the beginning, and PPC spread over time in regular amounts. If marketing budgets are applied in the wrong area, this could lead to losses and possibly financial ruin.

Objectives: The objective of this research was to investigate, using three real-world case studies, the actual expenditure on and income from both SEO and PPC systems. These figures were then compared, and specifically, the cost per acquisition (CPA) was used to decide which system yielded the best results.

Methodology: Three diverse websites were chosen, and analytics data for all three were compared over a 3-month period. Calculations were performed to reduce the figures to single ratios, to make comparisons between them possible.

Results: Some of the resultant ratios varied widely between websites. However, the CPA was shown to be on average 52.1 times lower for SEO than for PPC systems.

Conclusion: It was concluded that SEO should be the marketing system of preference for e-commerce-based websites. However, there are cases where PPC would yield better results when instant traffic is required, and when a large initial expenditure is not possible.

\section{Introduction}

Websites are created for several reasons, one of which is the representation of the business on the Internet. Although a website is not always considered the only way to represent an online business's presence, a website is arguably the most important entity that a business can create online. The reason is that the website is the virtual representation of the organisation, brand and products or services. This online representation determines how current and potential customers perceive the business, and it will define how customers will interact with the business. This indicates that anything and everything implemented on the website is of paramount importance. Miller (2011:17-27) lists several web marketing methods that should be considered if a website is to be marketed effectively online:

- Search Engine Optimisation (SEO): The concept is based on applying a search engine best practice methodology to any given website (this may require website alterations architecturally and/or otherwise), which will result in improved organic search engine rankings for topicrelated search queries (Weideman 2009).

- Pay-per-click (PPC) Advertising: PPC advertising is paid advertising on search engines and other display websites. It forms part of the search engine revenue model and functions on a keyword bidding system that depends on visitors who click on the advertisement.

- Online Advertising: This is commonly known as banner advertising; whereby graphical advertisements are placed on advertising publishing websites that have significant traffic volumes. The advertisements are paid for on a cost-per-impression basis and refer to the number of visitors who have viewed the advertisement.

- Email Marketing: Is referred to as 'push' marketing as the marketing message is pushed to the receiver's inbox. This also makes it a lot harder for the receiver to ignore the marketing message as opposed to an advertisement on a website. Email marketing is popular because of the following reasons: low cost, speed, simplicity, being proactive and targeting recipients.

- Blog Marketing: Blogs are used to make a more direct connection with customers. They are typically informative and personalise certain entities within the company. Blogs are often also used as a promotional channel for the business. 
- Social Media Marketing: Although blogs form part of social media marketing, social media is more focused on creating communities of various types that share information and current activities. In addition, consumers prefer to connect with consumers as they no longer blindly trust what businesses say. Informal consumer discussions (horizontal trust) are beginning to take precedence over business promises (vertical trust) (Kotler, Kartajaya \& Setiawan 2010:7).

- Online Public Relations: Also referred to as Press Releases, this is the publishing of press releases on other reliable, high-traffic volume and related industry websites that could drive traffic back to the business website.

- Multimedia Marketing: This includes both podcasting (audio) and digital video. The podcasts and videos could be hosted on other industry or topic-related websites as well as on the business website. Search engines often include different media formats in the search engine result pages (SERPs), which viewers often engage with owing to ease of use.

- Mobile Marketing: In recent years, more and more users have started to make use of mobile phones to access the Internet. This means that businesses need to re-evaluate not only websites and how they function on the mobile phone along with consumer expectations, but also other mobile advertising options such as SMS, banner and PPC advertising. More recently, the click-to-call function reduces the business response time delay, whereby the mobile user can simply click on the number on the advertisement to call the business without even visiting the website.

Each one of these marketing channels has a role to play in the overall marketing of a business website. However, for this study, a more in-depth analysis of PPC and SEO has been carried out. Why focus on PPC and SEO? According to Clarke and Clarke (2014), marketers typically use these two search engine marketing strategies. PPC is a scheme where marketers must submit a bid for one or more keywords or key phrases, then create the advertisements using minimal text to appear on user screens and pay the search engines only when a user clicks on one of the advertisements. The other strategy is SEO, which in turn involves many factors that the search engines use to determine relevance and ranking. These are normally categorised as being on-page, off-page and site-wide SEO.

Furthermore, the term 'cost per acquisition' (CPA) should be defined at this point because it has a prominent position in this research. In search engine marketing, the CPA is the average cost of acquiring customers or leads yielding customers. One accepted way of calculating the CPA is to divide the advertising cost by the number of customers (or leads) over a period. Some marketers use the terms CPA and cost per action interchangeably. CPA is one of a number of metrics used in measuring various attributes of e-commerce (Druckenmiller 2016; Pavel, Pauwels \& Gupta 2016).
Most prospective online shoppers are often overwhelmed by an oversupply of information, provided by search engines and other channels to find a relevant answer to their information needs (Broilo, Espartel \& Basso 2016). This further highlights the importance of providing answers to search queries high up on the SERPs, to ensure that user clicks are harvested. Both PPC and SEO strategies involve boosting rankings on a SERP, but there are key differences in where those results might appear (Olbrich \& Schultz 2014; see Figure 1).

However, this layout has changed in February 2016 when Google started implementing a large overhaul, which moved some of the advertisements from the right side to the bottom of the screen. Google also stated that it may show an additional advertisement (one extra ad on top of the original three) above the organic search results for what they called 'highly commercial queries' (McGee 2016). Presumably, this was done to provide better exposure for paying clients, instead of giving away some precious real estate at the top of the ranking lists to non-paying search results (see Figure 2 for the new layout).

In summary, recent publications (both in the general news and academic publications) seem to have stressed the importance of using both SEO and PPC in tandem (Google Analytics 2015; Gudivada, Rao \& Paris 2015; Jang, Lee \& Oh 2016; PRN 2015, 2016). These claims confirm the validity of having embarked on this research path. At the same time, there are voices of concern about the accuracy of some of the existing metrics used for e-commerce performance (Clarke \& Jansen 2017), but solutions proposed in this research have not been tested at the time of writing.

\section{Aims and objectives}

The aim of this study was to determine the best way to spend advertising resources. The objective was to measure and compare the CPA of SEO versus PPC, under comparable circumstances, which would give an indication of the most effective marketing spending pattern. These are critical issues, especially when companies are spending large amounts of money monthly to ensure the best possible exposure of their marketing efforts through websites and social media platforms (Baidya \& Basu 2011).

\section{Research problem}

It is important to budget properly for marketing expenditure because large amounts could be involved in certain markets (Baidya \& Basu 2011; Ford 1994). At the same time, money spent on marketing through PPC and SEO has been the topic of controversy (Kritzinger \& Weideman 2015). It appears as if more marketing dollars are spent on SEO, while PPC seems to yield higher income.

It has also been claimed that expenditure on marketing in especially larger companies has increased from $20 \%$ to $50 \%$ in around 50 years (Baidya \& Basu 2011).

The research problem is that financial losses can be incurred if marketing resources are misallocated, specifically when choosing between spending on SEO and PPC. 


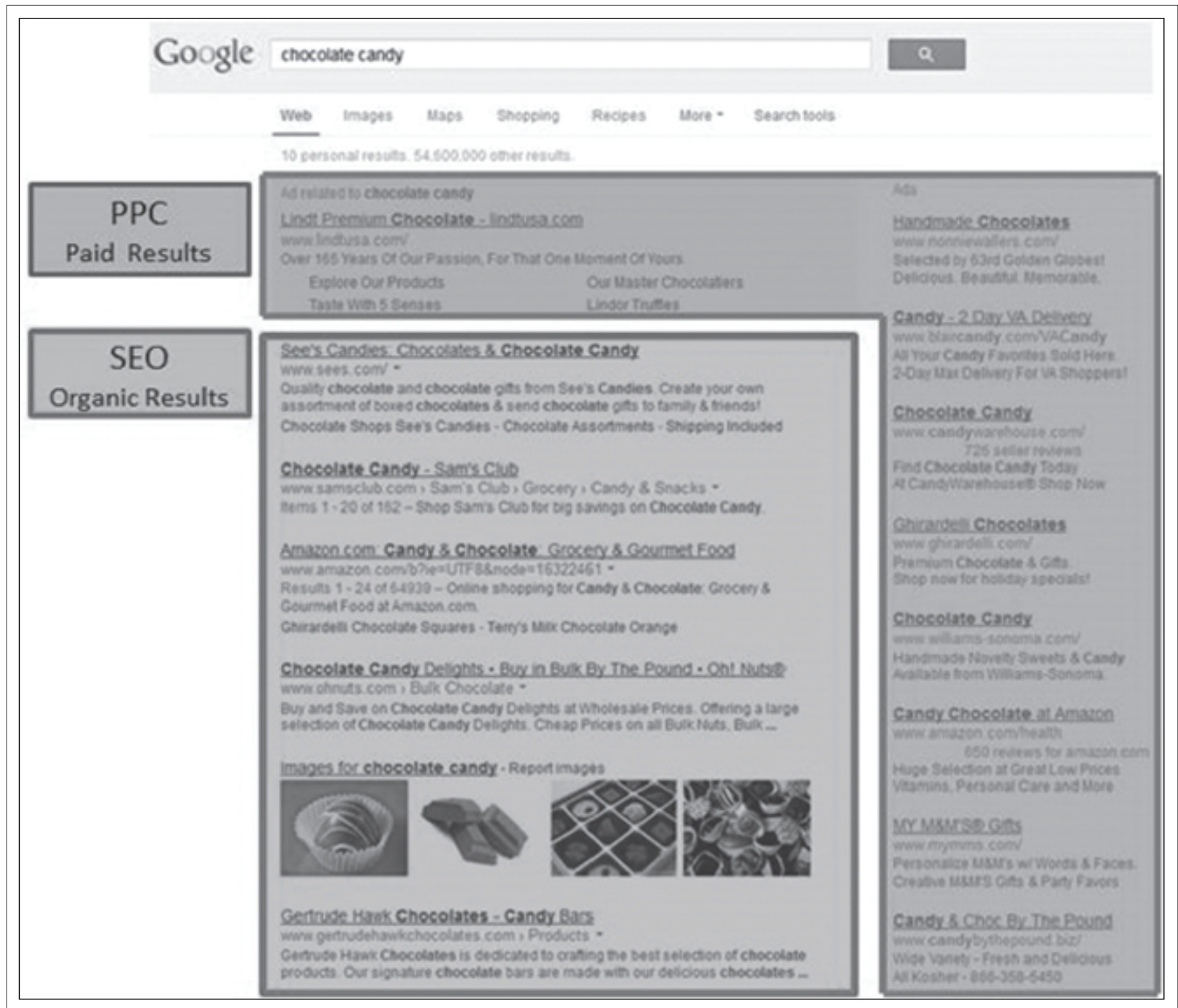

Source: Clarke, T.B. \& Clarke, I., 2014, 'A competitive and experiential assignment in search engine optimisation strategy', Marketing Education Review 24(1), 25-30. https://doi.org/10.2753/ MER1052-8008240104

FIGURE 1: Search engine result page locations for pay per click and search engine optimisation.

While attempting to address this problem through the research, a comparison will be made between cases where both SEO and PPC were used on different websites. The CPA will be calculated and compared because this figure is a good indication of the return on investment (ROI).

\section{Literature review}

A literature survey was conducted to determine what prior research has been done in this area. Key concepts such as SEO, PPC and CPA were studied.

\section{Introduction}

A brief explanation of how search engines index and rank web pages are given here for clarity. Search engines are companies that send programmes (called crawlers, robots, bots or spiders) to crawl the Internet, collecting the content of every web page they visit. This information is stored in an index (a complex database) for later use. When a user specifies a search query, the search engine algorithm examines the query, tries to determine what is that the user wants and then matches this information need as best it can with the website content it has stored in its index. The results are shown on the user's screen. Because there are almost always more than one possible answer, the search engine also has to decide in what order to display the answer, with the most relevant answer at the top (Weideman 2009).

Commercial motives coupled with inherent human laziness prescribes that the first few results on the results page are the ones that will receive the highest number of views. This has spawned the SEO industry, where websites are designed with search engine crawlers in mind, trying to ensure that every important web page will rank highly for a given search query. SEO techniques are divided into onpage and off-page types. On-page SEO refers to changes a 


\section{Google}

books for sale

\& $a$

All Images Books Maps News More Settings Tools

About 332000000 results $(1,16$ seconds)

takealot.com Buy Books - Widest Range of Books \& Authors

1. Add Www.takealot.com/Books-Sale -

Pay with Cash on Delivery - Free Delivery over R450 - Fast, Reliable Delivery - Millions of Prod cts

2 Cape Town Book Sale - Widest Range, Lowest Prices

2. Ad inw capetownbooksale co.za/ -

isisi Cape Town's biggest book sale from 16-18 June 2017 at the V\&A Waterfront. 3. Ad - South Africa - Buy Books Online - loot.co.za
Categories: Books, Movies \& TV, Games, Music, Computers...

Deal: $100 \%$ off Delivery-Orders R250

Cheaper for Free Delivery - MySchool Partner Program - Gift Vouchers - Slimkoppe Reeks

First 4 paid

ads - prime

position at

the top

Books Sale - gumtree.co.za

4. Sull Used Stuff for Sale. Official Gumtree web page.

You've visited gumtree.co.za many times. Last visit. 5 days ago

Books \& Games - Camping Gear - Musical Instruments - CDs \& DVDs

Buy Books \& eBooks Online: Children's, Fiction, Cooking, Academlc ...

1. Shop for Books \& eBooks online in South Africa. Fast, reliable delivery to your door. Lots of sal and

easy ways to pay. Safe, secure, online shopping for books.

Academic Books - School \& Education - Academic - Buy Childrens Books Online umw.lootco zarbooks -

R299 R249 Discovery Miles 2490 Mississippi Blood - The Natchez Trilogy. Book 3 (Paperback)

lles - Mississippi Blood - The Natchez Trilogy... Greg lles

The 10

organic

("unpaid")

results, listed

in the centre

Pimp My Book: Textbooks Bookshop Online Buy and Sell Books

10. unw pimpmybook co za/

Buy and Sell your textbooks here. We offer a wide range of the latest editions currently used in

Universities and Colleges in South Africa.

5. Ad w ww books sold online Fiction, non-fiction, collectors

Low prices ' Several shipping options ' Safe payment options

BooksAgain - Used fiction books online -Afrikaans fiction - Buy used nonfiction books

6. 150 million Books on Sale -

Cenpare prices from 100,000 sellers
Hard to find books - Get the best price - Includes shipping fees - Compare 100,000 sellers

First edition books - ISBN search - Textbook search - Signed books - Textbook buyback

Bepks for Sale Online - Worldwide Delivery - Buy Now [Ad] Www.gogoodbooks.com/ .

7. When you buy from Good Books the profit goes to Oxdam

Worldwide Shipping - Support Oxfam Projects · Used books · Brand New Books

Themes: Arts \& Photography, Biographies \& Memoirs, Business \& Money, Crafts, Hobbies \& Hor

\section{Last 3 paid ads - listed below the organic results}

Source: Huck, L., Hamner, K. \& Carpenter, C., 2016, How Google's new desktop SERP layout has impacted marketers, viewed 2 December 2016, from http://blog.360i.com/search-marketing/ googles-new-desktop-serp-layout-impacted-marketers

FIGURE 2: New search engine result page locations for pay per click and search engine optimisation. 
webmaster can make to the web pages under his or her control, where off-page techniques include things to be done outside the website at stake, to improve its ranking. Also, web page text must be written in an 'SEO-friendly' way, enabling crawlers and algorithms to easily detect what a given web page is really all about. On-page SEO includes the writing of 'good' meta-tags, Alt text for images, the correct use of $\mathrm{H} 1$ tags, well-written anchor text, file-name choices and others. Off-page SEO is mostly about creating an 'awareness' of the website at stake by building in-links (hyperlinks pointing from other website to the main website), and ensuring that many references about the main website are spread across the Internet. Unfortunately, the SEO industry also has its dark side - so-called black hat SEO is being practised, for example, by overstuffing a web page with keywords to appease the crawlers (Zuze \& Weideman 2013).

\section{Search engine optimisation}

To ensure a higher volume of human visitors, websites need to be visible to search engine crawlers. One important element in high rankings is how closely the contents of any given web page match the specification of a search engine for a 'good' website. This match is determined by a search engine algorithm. A process termed SEO can be used to improve how closely a website's layout matches the guidelines of the search engine. This process includes writing good content, ensuring a high number of links pointing to the website, plus many other factors. These are sometimes classified as either:

- on-page SEO (elements that are present (or absent) on the actual web page); or

- off-page SEO (elements that are not part of the website, but exist outside).

SEO is theoretically a once-off process because these changes will remain on the website after being implemented. However, the SEO done on a website must be updated over time. Search engines change their algorithms regularly, and competitor websites with high rankings could push down a given website on the SERPs.

SEO mostly involves a relatively large investment when done for the first time, with a much lower expense over time after that. Much research has been conducted to determine the best strategy to leverage SEO into ranking better on Google. Luh, Yang and Huang (2016) claimed that important keywords on the website should be incorporated into the URL, the page title and the snippet. Both Sullivan (2016) and Weideman (2009) have developed models to rank the SEO elements used by Google algorithms in the commercially important ranking of results on SERPs. However, many large retrieval systems suffer from low efficiency because of badly designed systems (including the ignorance of SEO principles), which makes it difficult for search engine crawlers to find information and return relevant results (Weideman 2015).

\section{Pay per click}

According to Yang et al. (2012:1141), there has been tremendous growth of search auctions when, as these authors put it, 'economics meet search'.

The same authors continue and explain that search auctions (or PPC) have now become one of the most used online advertising channels. So much so that search auctions now produce the primary revenue source for major search engines. Google has reported a total revenue of $\$ 8.44$ billion in the fourth quarter of 2010. Of this total, search auctions contributed 97\% (Yang et al. 2012:1141). Prior research has been conducted to reduce the negative effect of inefficient keyword bidding when running a PPC campaign (Nabout 2015).

Some studies have shown that, when faced with the choice, more users will click on SEO results than those clicking on PPC results (Neethling 2008; Panda 2013). This seems to confirm the existence of an anomaly as noted by Kritzinger and Weideman (2015). However, the PPC industry has grown into a multibillion-dollar industry and generates a large income to its hosts, including Google and Bing (Gupta \& Mateen 2014). This implies that the PPC system is successful and that it should be investigated.

\section{Cost per acquisition}

The CPA is an indication of the advertising cost of converting a human visitor into a paying client, producing revenue for the company. Ideally, the CPA should be low, which implies a higher profit rate. It has been claimed that acquiring a new customer could cost five times more than that to retain an existing one (Pfeifer 2005). This confirms the importance of determining which marketing method produces the lowest CPA.

\section{Methodology}

The best approach for this project was considered to be comparative and empirical. A convenience sample of three websites was used because all the historical data required for the research could be retrieved from these three, and all three had (a) product(s) to sell. Various user activities, as well as company expenditures were monitored and recorded over a period because they were all required to do the final CPA calculations.

For this research project, the authors examined the analytics and other statistical usage results of three real-life websites where both PPC and SEO of the marketing approaches were followed in tandem. The three websites are from three distinct industries and had no relation to each other.

The names of the three companies are not listed here - for brevity's sake, they will be referred to as Website 1, 2 and 3 . All three companies invested in SEO and PPC on their websites. Website 1 is in the Bedding and Linen industry that is based in South Africa. They are an e-commerce concern. 
In contrast, Website 2 is in the Toys Retail Industry and is based in the United Kingdom. Lastly, Website 3 is in the Road-Side Assistance Industry and is based in South Africa. Website 3 is not an e-commerce website, so an alternative way to measure transactions and actual income had to be found. For this research, the authors considered Goal Conversion specifically, that is, the number of new membership sign ups. This metric was roughly equivalent to an indication of sales because both generate direct income for the company.

The three websites were monitored for a period of 90 days (3 months). Usage behaviour and statistics were recorded and analysed to compare the expenditures with the gains, more specifically the CPA for each of these test websites.

Each of these websites was running an AdWords Campaign over the 90-day period they were monitored. All three were also running SEO campaigns alongside PPC Campaigns. The AdWords costs were recorded for each of the three websites as well as the monthly SEO cost over the 3-month period.

For the two e-commerce websites (Websites 1 and 2), the following statistics were recorded for both the PPC and SEO campaigns, for the 3-month period:

- the number of clicks received for both the paid and organic section of Google's search results page

- the number of user sessions recorded

- the average bounce rate

- the average number of pages per session

- the e-commerce conversion rate

- the number of transactions recorded

- the total revenue after 3 months for both PPC and SEO.

The e-commerce conversion rate is the percentage of sessions that resulted in an e-commerce transaction. For example, if a website had 17352 sessions in a month and these sessions resulted in 188 transactions, then the e-commerce conversion rate would be $(188 / 17352) \times 100=1.08 \%$.

For Website 3 (the non-e-commerce website), the same statistics were also recorded for both PPC and SEO other the 3 months with these exceptions:
- The e-commerce conversion rate was replaced with 'goal conversion rate'.

- No revenue was recorded because the website is not e-commerce enabled.

\section{Results and analysis}

For the results and interpretation, the focus will firstly be on Websites 1 and 2 (the e-commerce websites).

\section{Website 1}

\section{Clicks}

For Website 1, the test period was from 07 September 2015 to 05 December 2015. The total number of organic clicks (SEO clicks) was retrieved from Google's Web Console.

Figure 3 indicates that Website 1 received 56334 clicks from organic search results over the test period. This resulted in 57475 organic sessions. The organic sessions were retrieved from Google Analytics (see Figure 4).

From the 57475 organic sessions, the website analytics recorded 219 e-commerce transactions with a total revenue of R314 078.50, as shown in Figure 5.

Website 1 received 28926 clicks from the Adwords Campaign (PPC Campaign) - this produced 29795 PPC sessions. From these sessions, a total of 178 transactions were recorded over the 3-month period. This produced a PPC revenue of R238 925.60 (see Figure 6).

To summarise the results for Website 1, refer to Table 1.

\section{Ratios}

The values in the PPC and SEO columns were extracted from the Google Analytics records, while the Ratio column figures were calculated as a ratio of the previous two column values. Figures in the Ratio column were rounded to one decimal place. In all cases, a decision was taken in terms of how the ratio was to be calculated, to enable easier interpretation of the table data. For any given two sets of figures, a ratio of 1 (1:1) would mean that SEO and PPC performed identically. It was decided randomly (because

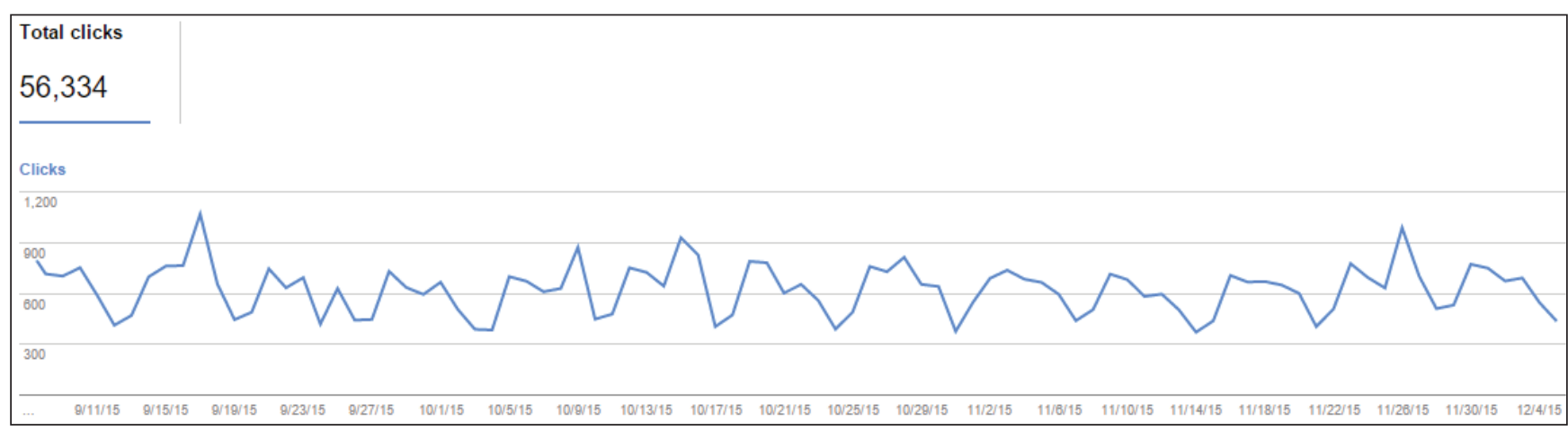

Source: Google Analytics, 2016, Google Analytics Report, viewed 16 May 2017, from https://www.google.com/analytics FIGURE 3: Clicks harvested from Website 1. 


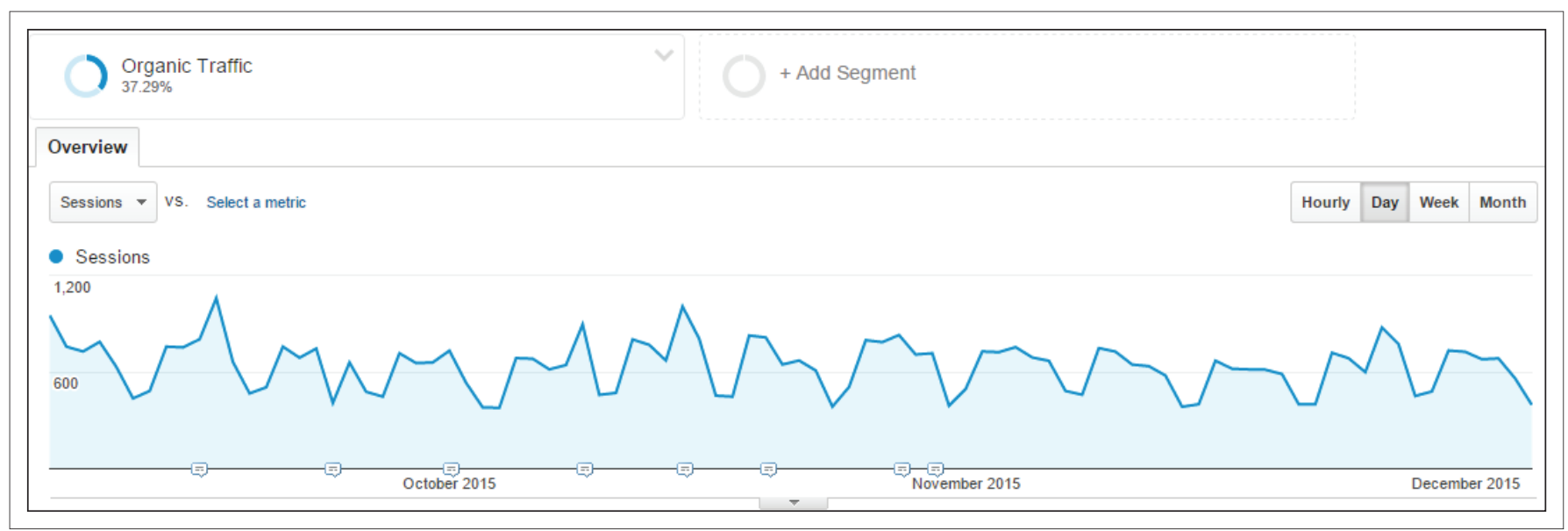

Source: Google Analytics, 2016, Google Analytics Report, viewed 16 May 2017, from https://www.google.com/analytics FIGURE 4: User sessions recorded on Website 1.

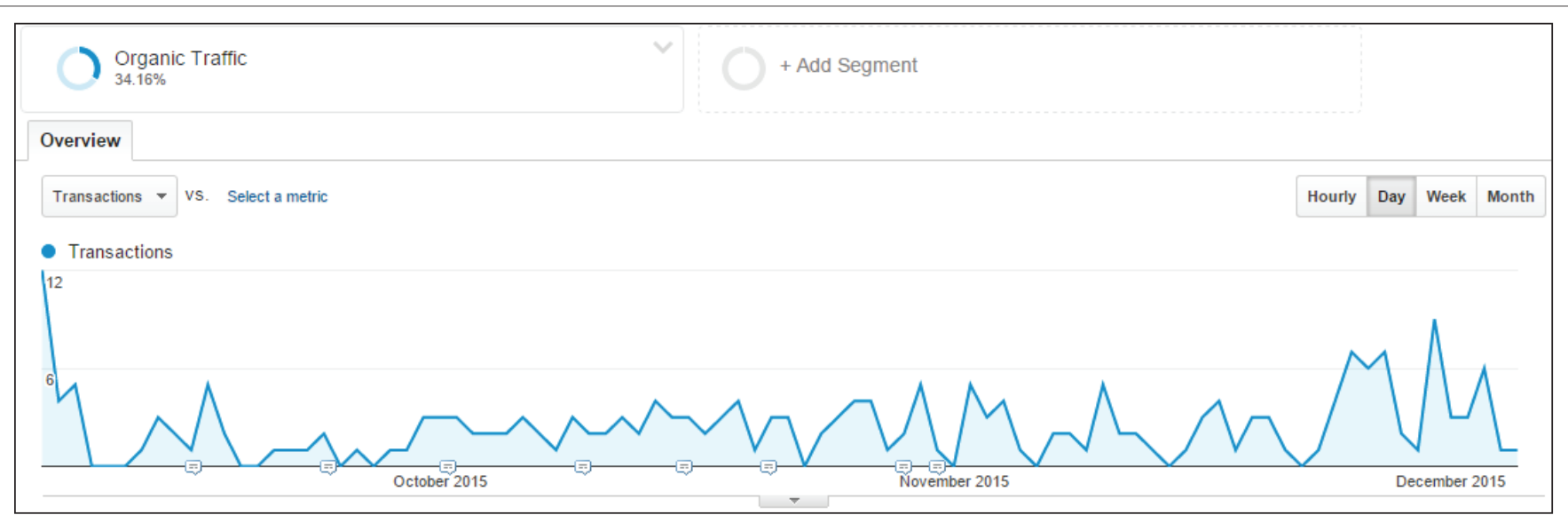

Source: Google Analytics, 2016, Google Analytics Report, viewed 16 May 2017, from https://www.google.com/analytics

FIGURE 5: The e-commerce transactions recorded on Website 1.

only the ratio and not the actual figures matter) that if the PPC and SEO figures for a given row indicated that SEO performed better than PPC (e.g. SEO produced more clicks, or SEO cost less than PPC), then the calculation would be performed in a way that the ratio would be above 1 . This would allow for easier interpretation of results because a figure higher than 1 would always signify 'better' for SEO and 'worse' for PPC.

When considering the values of Table 1, note that higher values are more desirable than lower ones: Clicks, Sessions, Pages/session, e-commerce conversion rate, Transactions and Revenue. The remaining measures need to be lower to be better: Cost, Cost per click (CPC), Bounce rate and CPA. This difference is merely a result of the way these metrics were designed to indicate a given value for a given attribute. More clicks, more transactions and higher revenue are better, while lower values for expenditure (costs) and unimpressed users are better.

The figures in Table 1 can be classified into two types:

- those that do not have real value in terms of ROI, mostly isolated figures which do not depend on any other value (called incidental from here on - indicated in normal type)
- those that carry weight in terms of ROI, in the sense that they provide an indication of value (called indicative from here on - indicated in bold type).

From Table 1, over the test period of 3 months, a combined cost of R84 918.68 was incurred. PPC represents $68 \%$ of the total cost, while SEO represents the remaining $32 \%$. The total number of clicks received was 85260 . SEO represents $66 \%$ of the total clicks, while PPC represents the remaining $34 \%$. This is almost the exact reverse of the cost split between PPC and SEO.

Also from Table 1, the CPC for PPC was R1.99 and for SEO was R0.48 for SEO - the CPC for SEO is four times lower than the CPC for PPC. The bounce rates for PPC and SEO were relatively close to being the same at $29.61 \%$ and $23.59 \%$, respectively. The e-commerce conversion rate for PPC is slightly higher than that of the SEO e-commerce conversion rate, at $0.6 \%$ and $0.38 \%$, respectively. This indicates that PPC visitors are slightly more likely to convert than those arriving on a site through SEO results.

Finally, when comparing the total revenue, it was found that PPC resulted in R238 925.60 (or 43\%) of the total revenue 


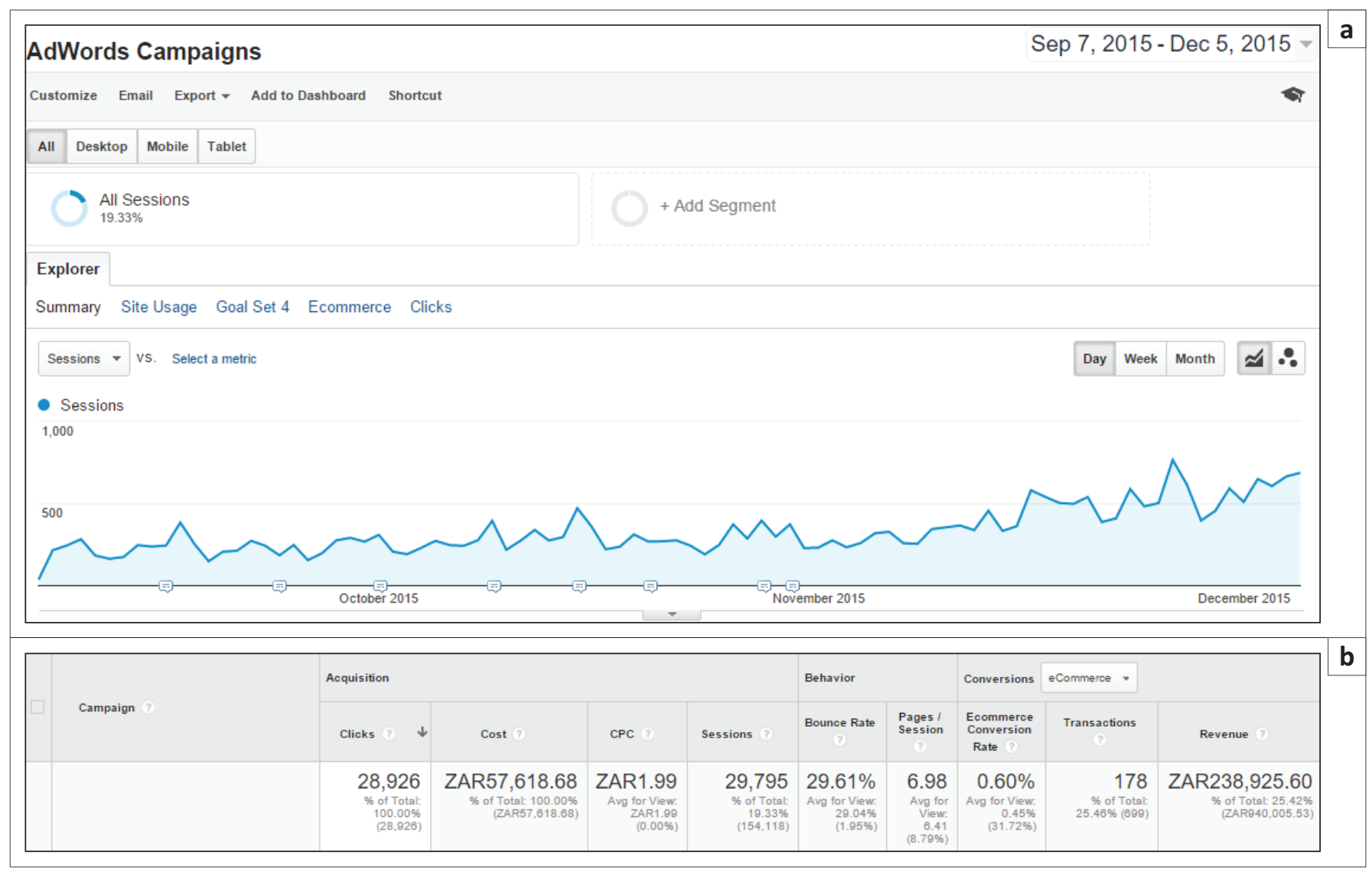

Source: Google Analytics, 2016, Google Analytics Report, viewed 16 May 2017, from https://www.google.com/analytics

FIGURE 6: Transactions recorded on Website 1: (a) number of user sessions recorded over the 3-month period and (b) session details: acquisition, behaviour and conversions.

TABLE 1: Results for Website 1.

\begin{tabular}{llll}
\hline Website 1 & PPC & SEO & Ratio-PPC:SEO \\
\hline Clicks & 28926 & 56334 & 1.9 \\
Cost & R57 618.68 & R27 300.00 & 2.1 \\
CPC & $\mathbf{R} 1.99$ & R0.48 & $\mathbf{4 . 1}$ \\
Sessions & 29795 & 57475 & 1.9 \\
Bounce rate & $29.61 \%$ & $23.59 \%$ & 1.3 \\
Pages/sessions & 6.98 & 7.21 & 1.0 \\
e-commerce conversion rate & $\mathbf{0 . 6 0 \%}$ & $\mathbf{0 . 3 8 \%}$ & $\mathbf{0 . 6}$ \\
Transactions & 178 & 219 & 1.2 \\
\hline Revenue & R238 925.60 & R314 078.50 & 1.3 \\
\hline CPA & R333.43 & R127.18 & $\mathbf{2 . 6}$ \\
\hline
\end{tabular}

Source: Google Analytics, 2016, Google Analytics Report, viewed 16 May 2017, from https:// www.google.com/analytics

CPA, cost per acquisition; CPC, cost per click; PPC, pay per click; SEO, search engine optimisation.

received over the 3-month period. SEO resulted in R31 4078.50 (or $57 \%$ ) of the total revenue.

In summary, three of the calculated ratios are indicative and two of the three favour SEO. This includes the most important measure, the CPA.

\section{Website 2}

\section{Clicks}

For Website 2 the test period was from 17 January 2016 to 15 April 2016. The total number of organic clicks (SEO clicks) was retrieved from Google's Web Console (see Figure 7).
As can be seen from Figure 7, Website 2 received 3871508 clicks from organic search results over the test period. This resulted in 4872537 organic sessions. The organic sessions were retrieved from Google Analytics (see Figure 8).

From the 4872537 organic sessions (see Figure 8), the website received 41186 e-commerce transactions with a total revenue of $£ 2163584.37$ (see Figure 9).

From the Adwords Campaign (PPC Campaign), Website 2 received 322483 clicks, which resulted in 442399 PPC sessions. From the 442399 PPC sessions, a total number of 7869 transactions were recorded over the 3-month period, which resulted in a PPC revenue of $£ 354876.22$ (see Figure 10).

For a summary of the results for Website 2, see Table 2.

From Table 2, the authors found that over the test period of 3 months a combined cost of $£ 88966.82$ was incurred. PPC represents $96 \%$ of the total cost, while SEO represents the remaining $4 \%$. In contrast, the total number of clicks harvested over the 3-month period was 4193 991. SEO represents $92 \%$ of the total clicks, while PPC represents the remaining $8 \%$. This is almost the complete reverse of the cost split between PPC and SEO. 


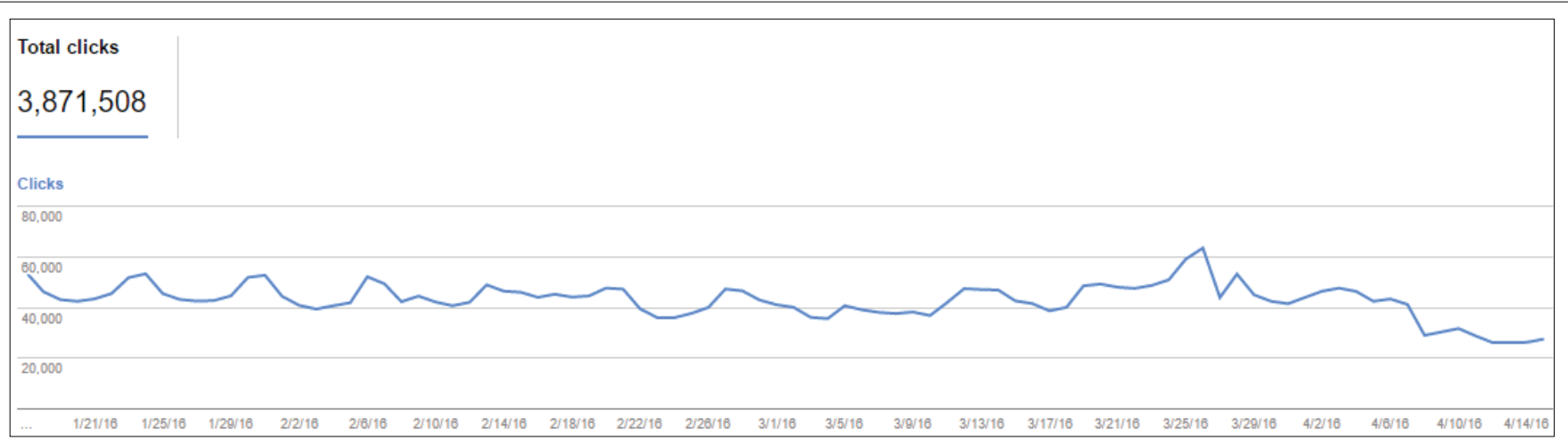

Source: Google Analytics, 2016, Google Analytics Report, viewed 16 May 2017, from https://www.google.com/analytics FIGURE 7: Clicks harvested from Website 2.

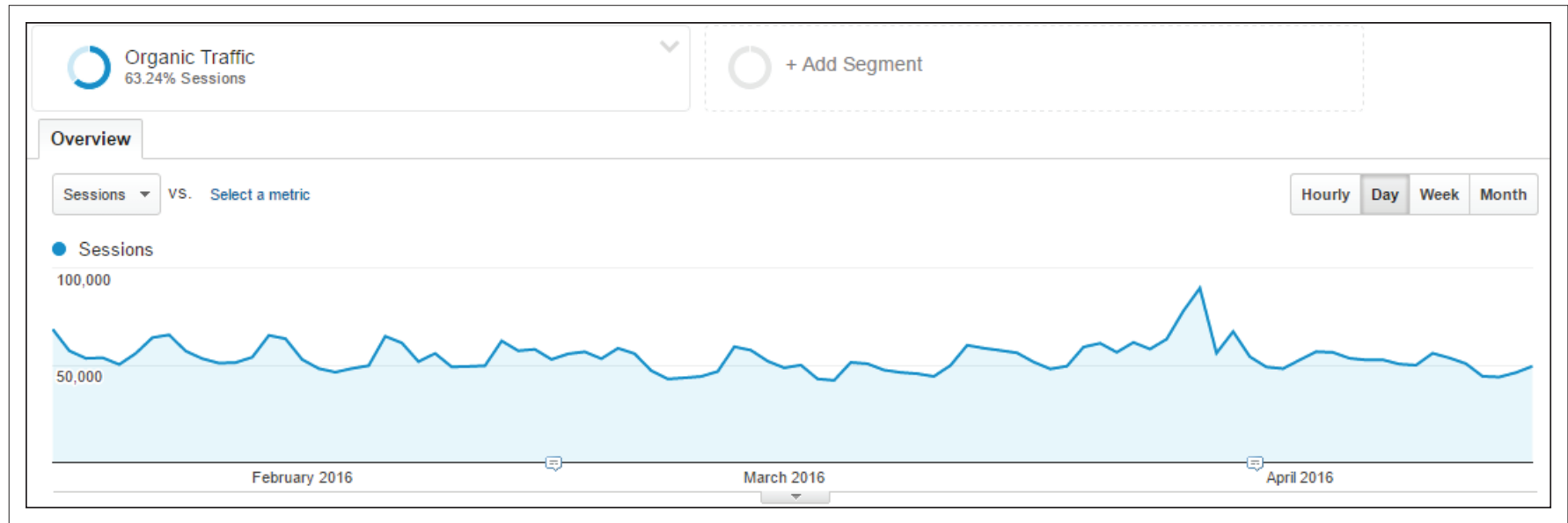

Source: Google Analytics, 2016, Google Analytics Report, viewed 16 May 2017, from https://www.google.com/analytics

FIGURE 8: User sessions recorded on Website 2.

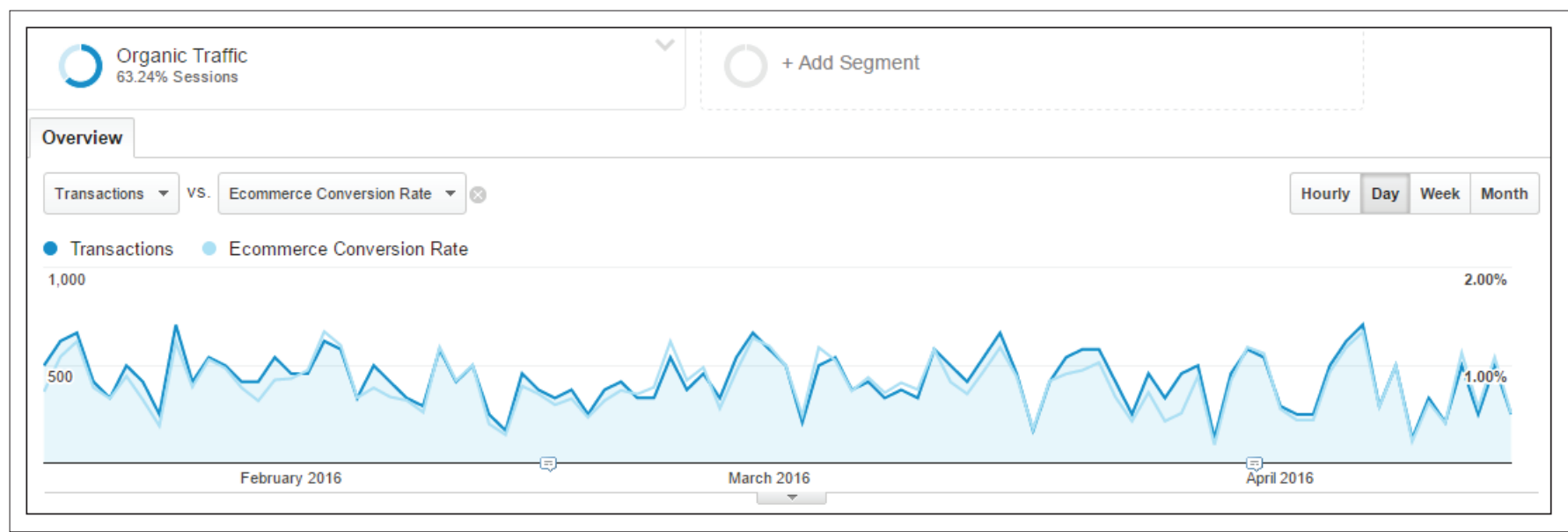

Source: Google Analytics, 2016, Google Analytics Report, viewed 16 May 2017, from https://www.google.com/analytics FIGURE 9: The e-commerce transactions recorded on Website 2.

From the numbers in this table, it became clear that the CPC for PPC was $£ 0.27$ and $£ 0.00087$ for SEO. The CPC for SEO is significantly lower than the CPC for PPC. The bounce rates for PPC and SEO were very different at 59.55\% and $26 \%$, respectively. The e-commerce conversion rate for PPC is higher than that of the SEO e-commerce conversion rate $1.78 \%$ and $0.85 \%$, respectively. This means that PPC visitors are slightly more likely to convert.
Finally, when the authors compared the total revenue, it was found that PPC resulted in $£ 354876.22$ (or 16\%) of the total revenue received over the 3 -month period. SEO resulted in $£ 2163584.37$ (or $84 \%$ ) of the total revenue.

In summary, three of the calculated ratios are indicative, and two of the three favour SEO. This includes the most important measure, the CPA. 


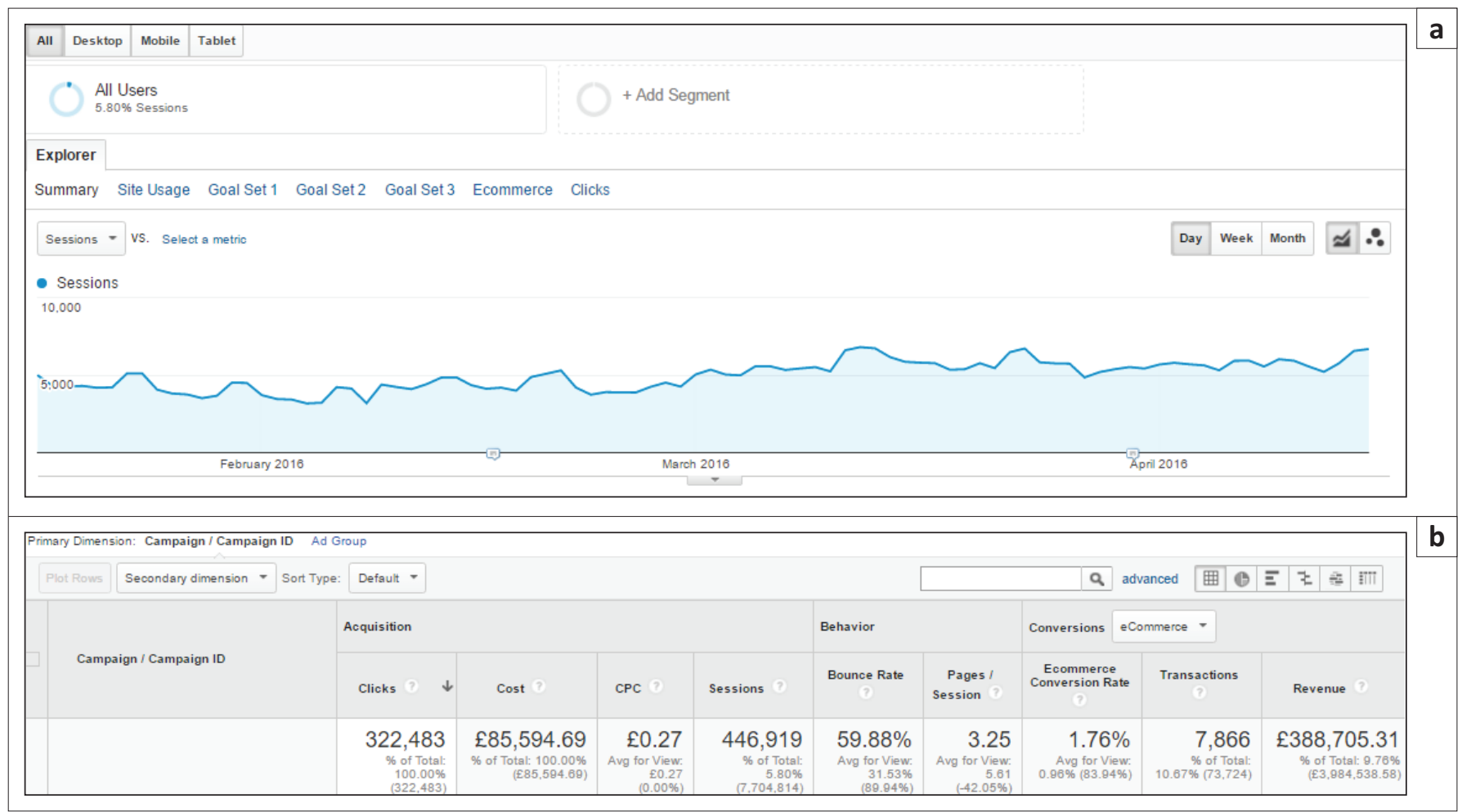

Source: Google Analytics, 2016, Google Analytics Report, viewed 16 May 2017, from https://www.google.com/analytics

FIGURE 10: Transactions recorded on Website 2: (a) number of user sessions recorded over the 3-month period and (b) session details: acquisition, behaviour and conversions.

TABLE 2: Results for Website 2.

\begin{tabular}{|c|c|c|c|}
\hline Website 2 & PPC & SEO & Ratio - PPC:SEO \\
\hline Clicks & 322483 & 3871508 & 12 \\
\hline Cost & f85 594.69 & £3372.13 & 25.4 \\
\hline CPC & $£ 0.27$ & $£ 0.00087$ & 310.3 \\
\hline Sessions & 442399 & 4872537 & 11 \\
\hline Bounce rate & $59.55 \%$ & $26 \%$ & 2.3 \\
\hline Pages/sessions & 3.19 & 6.08 & 1.9 \\
\hline e-commerce conversion rate & $1.78 \%$ & $0.85 \%$ & 0.5 \\
\hline Transactions & 7869 & 41186 & 5.2 \\
\hline Revenue & f354 876.22 & f2 163584.37 & 6.1 \\
\hline CPA & f14.92 & f0.10 & 149.2 \\
\hline
\end{tabular}

Source: Author's own based on data extracted from Google Analytics reports CPA, cost per acquisition; CPC, cost per click; PPC, pay per click; SEO, search engine optimisation.

\section{Website 3}

\section{Clicks}

For Website 3, the test period was from 8 September 2015 to 6 December 2015. The total number of organic clicks (SEO clicks) was retrieved from Google's Web Console.

As can be seen from Figure 11, Website 3 received 296101 clicks from organic search results over the test period. This resulted in 319660 organic sessions. The organic sessions were retrieved from Google Analytics (see Figure 12).

From the 319660 organic sessions, the website received 1573 goal completions (see Figure 13).

From the Adwords Campaign (PPC Campaign), Website 3 received 59838 clicks, which resulted in 19572 PPC sessions.
From the 19572 PPC sessions, a total number of 811 goals were recorded over the 3-month period (see Figure 14).

To summarise the results for Website 3 , see Table 3.

From Table 3 the authors found that over the test period a combined cost of R315 592.29 was incurred. PPC represents 88\% of the total cost, while SEO represents the remaining $12 \%$ of the total cost. In contrast, the total number of clicks received over the 3-month period was 355939 . SEO represents $83 \%$ of the total clicks, while PPC represents the remaining 17\%. This is almost the complete reverse of the cost split between PPC and SEO.

From the figures in Table 3, the authors also found that the CPC for PPC was R4.68 and R0.13 for SEO. The CPC for SEO is 36 times lower than the CPC for PPC. The bounce rates for PPC and SEO were also very different at $66.73 \%$ and $41.29 \%$, respectively. The goal conversion rate for PPC was higher than that of the SEO goal conversion rate $-4.14 \%$ and $0.49 \%$, respectively. This means that PPC visitors are significantly more likely to convert.

In summary, three of the calculated ratios are indicative, and two of the three favour SEO. This includes the most important measure, the CPA.

\section{Conclusion \\ Limitations and recommendations}

It was considered necessary to investigate why Website 2 had such extreme figures favouring SEO. Website 2 is that 


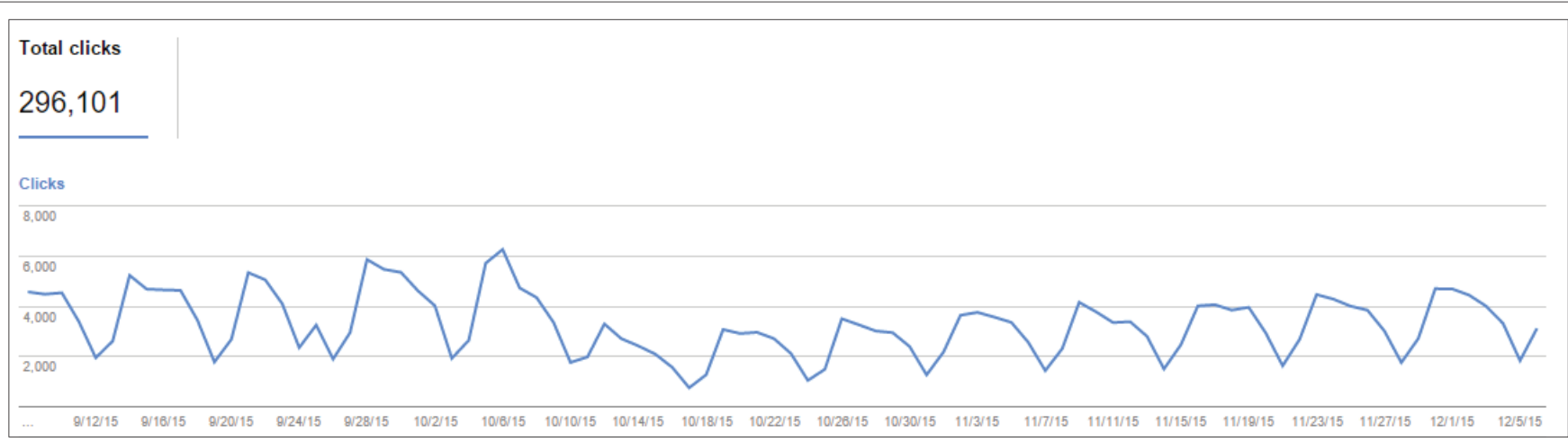

Source: Google Analytics, 2016, Google Analytics Report, viewed 16 May 2017, from https://www.google.com/analytics FIGURE 11: Clicks harvested from Website 3.

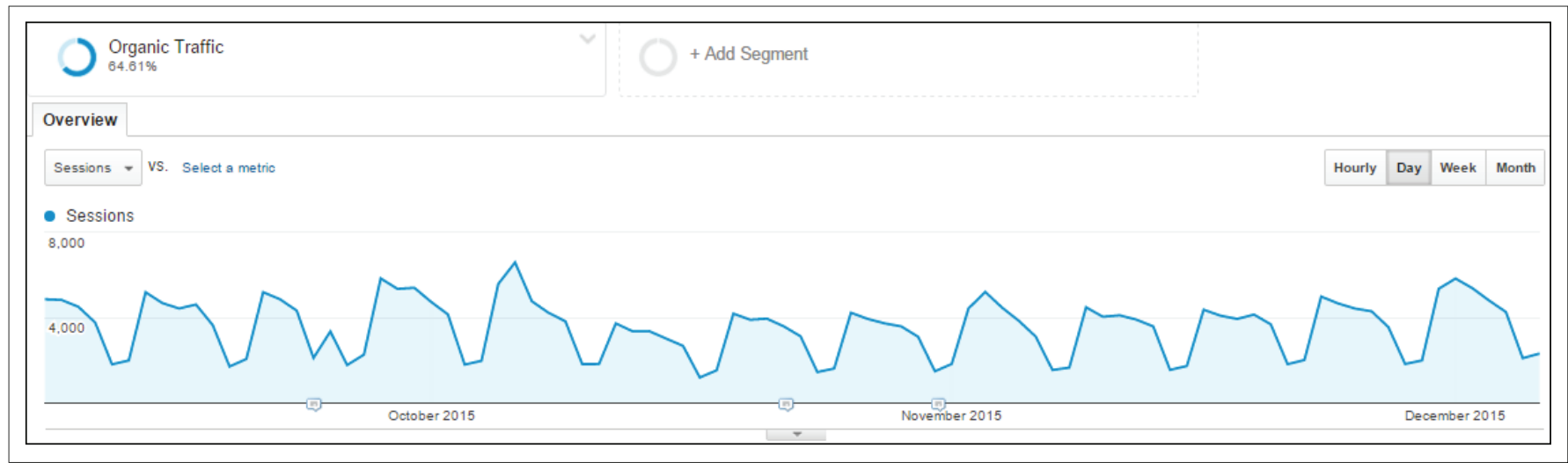

Source: Google Analytics, 2016, Google Analytics Report, viewed 16 May 2017, from https://www.google.com/analytics FIGURE 12: User sessions recorded on Website 3.

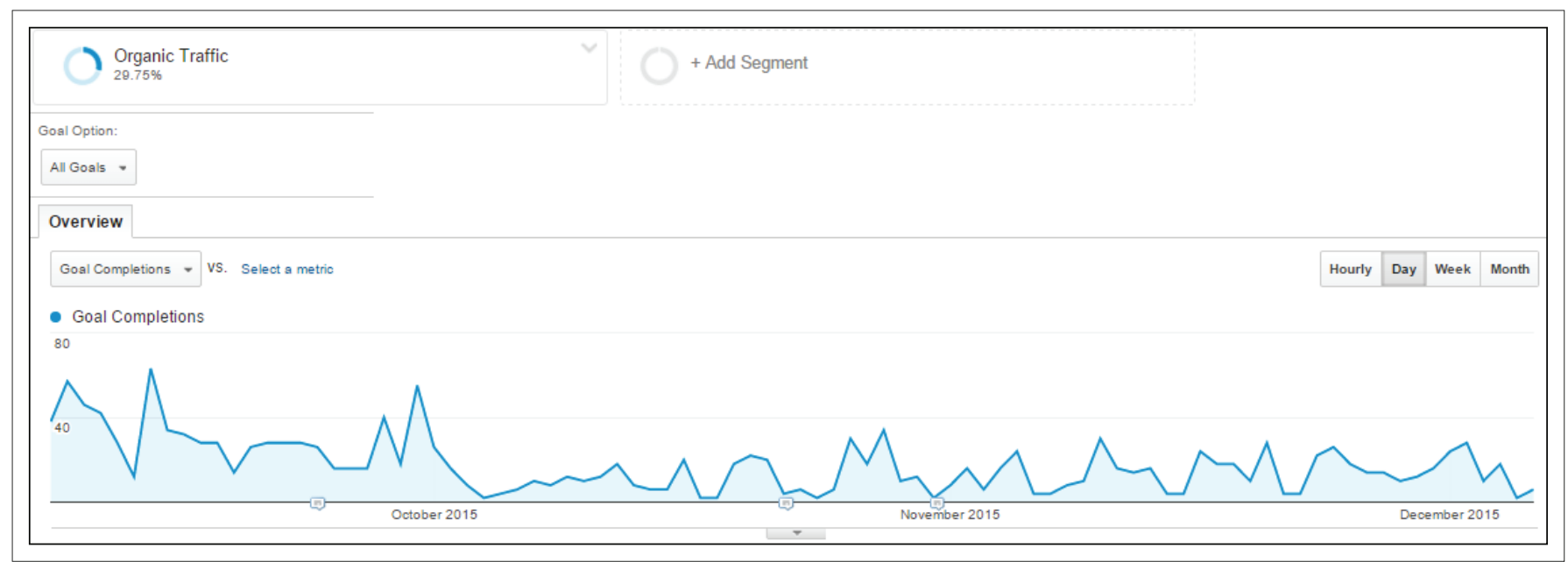

Source: Google Analytics, 2016, Google Analytics Report, viewed 16 May 2017, from https://www.google.com/analytics FIGURE 13: The e-commerce transactions recorded on Website 3.

of ' $\mathrm{n}$ major toy retail store in the UK and Ireland. They have literally hundreds of different Product Categories and thousands of Products being sold. Each one of these category and product pages were built on SEO best practice. This has resulted in a very large number of web pages with a high search engine ranking, resulting in a high number of visits from searchers clicking on natural results. The large difference in user sessions between SEO and PPC (4 872537 vs. 442 399) confirms this claim. Hence, this specific website has a much better ranking on natural results than the other two, smaller websites. This fact clarifies the higher SEOsupporting figures.

Finally, a further summary of the results from the three websites' figures and ratios was needed before drawing conclusions. In Table 4, the most indicative figures from the three website data tables are summarised.

It is clear that all three websites show the same trends, but to different degrees: 


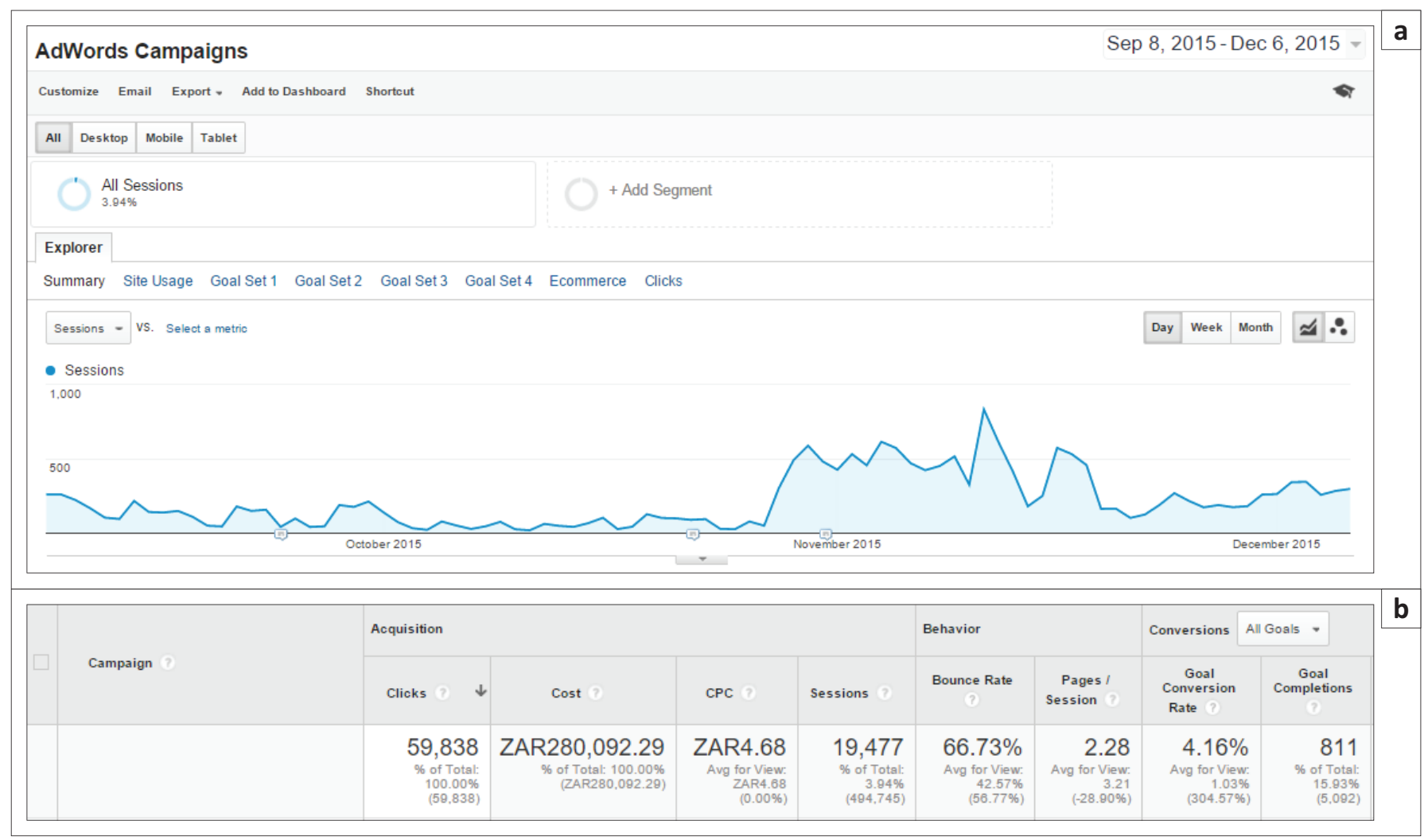

Source: Google Analytics, 2016, Google Analytics Report, viewed 16 May 2017, from https://www.google.com/analytics

FIGURE 14: Transactions recorded on Website 3: (a) number of user sessions recorded over the 3-month period and (b) session details: acquisition, behaviour and conversions.

TABLE 3: Results for Website 3.

\begin{tabular}{llll}
\hline Website 3 & PPC & SEO & Ratio-PPC:SEO \\
\hline Clicks & 59838 & 296101 & 5.0 \\
Cost & R280 092.29 & R37 500.00 & 7.5 \\
CPC & $\mathbf{R 4 . 6 8}$ & $\mathbf{R 0 . 1 3}$ & $\mathbf{3 6 . 0}$ \\
Sessions & 19572 & 319660 & 16.3 \\
Bounce rate & $66.73 \%$ & $41.29 \%$ & 1.6 \\
Pages/sessions & 2.28 & 3.25 & 1.4 \\
Goal conversion rate & $\mathbf{4 . 1 4 \%}$ & $\mathbf{0 . 4 9 \%}$ & $\mathbf{0 . 1}$ \\
Transactions & 811 & 1573 & 1.9 \\
CPA & $\mathbf{R 1 1 2 . 9 6}$ & $\mathbf{R 2 5 . 8 5}$ & $\mathbf{4 . 4}$ \\
\hline
\end{tabular}

Source: Author's own based on data extracted from Google Analytics reports CPA, cost per acquisition; CPC, cost per click; PPC, pay per click; SEO, search engine optimisation.

- CPC: All three websites favour SEO, with Website 1 showing a relatively small difference and Website 2 showing a dramatic difference. A lower CPC can, therefore, be achieved through the use of SEO. Of all three measures, CPC has the highest degree of difference, with an average SEO preference of 116.8.

- Conversion rate: All three websites favour PPC, with Website 1 showing a relatively large difference and Website 3 showing a small difference. A higher Conversion Rate can be achieved using PPC. Of all three measures, Conversion Rate has the lowest degree of difference, with an average PPC preference of 0.4.

- CPA: All three websites favour SEO, with Website 1 showing a relatively small difference and Website 2 showing a dramatic difference. It can, therefore, be concluded that a lower CPA can be achieved using SEO. The average CPA for the three websites is 52.1.
TABLE 4: Website comparative results.

\begin{tabular}{llll}
\hline Measure & Website $\mathbf{1}$ & Website 2 & Website 3 \\
\hline CPC & 4.1 & 310.3 & 36.0 \\
Conversion rate & 0.6 & 0.5 & 0.1 \\
CPA & 2.6 & 149.2 & 4.4 \\
\hline
\end{tabular}

CPA, cost per acquisition; CPC, cost per click.

The focus of this research was on a comparison between the CPA of SEO versus PPC systems, so these figures require more attention. The CPA figure is 52.1 times higher on the average for PPC systems than for SEO. So, if an online retailer must spend, for example, R1000 per month to acquire sales through SEO, they will need to spend R52 100 during the same month through PPC for the same returns. A higher number of websites need to be compared for a reliable average figure, so this research can lead to some follow-up work using more websites.

In conclusion, the results clearly show that SEO produces a much lower CPA, which is, therefore, a better choice of marketing strategy for any online retailer.

Limitations of the study include that only three websites were used - more websites in the sample would yield more accurate results. Also, figures spanning a longer period would produce more stable results.

As recommendation, it is suggested that most of a company's marketing budget be spent on SEO. However, in certain isolated cases, PPC could be a better choice. Examples where this could be the case include: 
- when immediate results are imperative

- when regular expenditure per month is preferable over an initial high investment.

In the first case, PPC would be better because one's PPC ads can start playing immediately after the system and accounting has been set up, possibly harvesting paying clients with virtually no delay (Kritzinger \& Weideman 2013). With SEO, time must be allowed for SEO implementation, before search results could bring in clients.

Secondly, if SEO on a given website is non-existent or badly performed, it could require a major financial investment before results of an SEO campaign will become evident. In some situations, the client might not have the financial means to invest a large amount up front and might choose to rather spread the financial outlay over a period. In this case, after a given period the PPC expenditure might cross over that of what the SEO costs might have been and then an SEO investment might have been better in the long run. It has been proven in previous research that this time period can typically be around 6 months (Kritzinger \& Weideman 2013).

Finally, the following recommendations were evident from this research:

- Use PPC if quick results are essential and if a more piecemeal way of spending a limited budget is needed.

- Use SEO for results at a lower overall cost, when considering the amount spent to achieve those results.

- Use both approaches in tandem in a systematic, carefully balanced long-term approach to ensure high rankings, high visitor counts, high income and eventually a higher ROI (Kritzinger \& Weideman 2013).

\section{Acknowledgements Competing interests}

The authors declare that they have no financial or personal relationships that may have inappropriately influenced them in writing this article.

\section{Authors' contributions}

W.T.K., the doctoral student, did the actual research, recorded the results and wrote $50 \%$ of the article. M.W., the supervisor, completed the other $50 \%$ of the article, did the proofreading, checked the content, formatted the article, added references and submitted the article for publication. After feedback from reviewers, he also did all corrections and improvements.

\section{References}

Baidya, M.K. \& Basu, P., 2011, 'Allocation of budget on marketing efforts: An econometric approach in India', Asia Pacific Journal of Marketing and Logistics 23(4), 501-512. https://doi.org/10.1108/13555851111165057

Broilo, P.L., Espartel, L.B. \& Basso, K., 2016, 'Pre-purchase information search: Too many sources to choose', Journal of Research in Interactive Marketing 10(3), 193-211. https://doi.org/10.1108/JRIM-07-2015-0048
Clarke, T.B. \& Clarke, I., 2014, 'A competitive and experiential assignment in search engine optimisation strategy', Marketing Education Review 24(1), 25-30. https:// engine optimisation strategy', Marketing
doi.org/10.2753/MER1052-8008240104

Clarke, T.B. \& Jansen, B.J., 2017, 'Conversion potential: A metric for evaluating search engine advertising Performance', Journal of Research in Interactive Marketing 11(2). https://doi.org/10.1108/JRIM-07-2016-0073

Druckenmiller, G., 2016, 'How to cut cost per acquisition in half and drive more leads without increasing budget', Webinar Presented by Evariant, 03 July 2016, Farmington, CT, Businesswire, bizwire.c67271458.

Ford, R.A.M.B.J., 1994, 'Relationship between marketing planning and annual budgeting', Marketing Intelligence \& Planning 12(1), 22-28. https://doi.org/ 10.1108/02634509410052621

Google Analytics, 2015, 'Making sponsored search ads work better', Strategic Direction 31(1), 12-14. https://doi.org/10.1108/SD-10-2014-0155

Google Analytics, 2016, Google Analytics Report, viewed 16 May 2017, from https:// www.google.com/analytics

Gudivada, V.N., Rao, D. \& Paris, J., 2015, 'Understanding search-engine optimization', Computer 162(15), 43-52. https://doi.org/10.1109/MC.2015.297

Gupta, A. \& Mateen, A., 2014, 'Exploring the factors affecting sponsored search ad performance', Marketing Intelligence \& Planning 32(5), 586-599. https://doi. org/10.1108/MIP-05-2013-0083

Huck, L., Hamner, K. \& Carpenter, C., 2016, How Google's new desktop SERP layout has impacted marketers, viewed 2 December 2016, from http://blog.360i.com/ search-marketing/googles-new-desktop-serp-layout-impacted-marketers

Jang, W., Lee, E. \& Oh, S.G., 2016, 'Search engine optimization', Library Hi Tech 34(2), 197-206. https://doi.org/10.1108/LHT-02-2016-0014

Kotler, P., Kartajaya, H. \& Setiawan, I., 2010, Marketing 3.0: From products to customers to the human spirit, John Wiley, Hoboken, NJ.

Kritzinger, W.T. \& Weideman, M., 2013, 'Search engine optimization and pay-per-click marketing strategies', Journal of Organizational Computing and Electronic Commerce 23(3), 273-286. https://doi.org/10.1080/10919392.2013.808124

Kritzinger, W.T. \& Weideman, M., 2015, 'Comparative case study on website traffic generated by search engine optimisation and a pay-per-click campaign, versus marketing expenditure', South African Journal of Information Management 17(1), Art. \#651, 1-12. https://doi.org/10.4102/sajim.v17i1.651

Luh, C.J., Yang, S.A. \& Huang, T.L.D., 2016, 'Estimating Google's search engine ranking function from a search engine optimization perspective', Online Information Review 40(2), 239-255. https://doi.org/10.1108/OIR-04-2015-0112

McGee, M., 2016, Confirmed: Google to stop showing ads on the right side of desktop search results worldwide, viewed 05 December 2016, from $\mathrm{http}: / /$ searchengineland. com/google-no-ads-right-side-of-desktop-search-results-242997

Miller, M., 2011., The ultimate web marketing guide, Pearson Education, Indianapolis, IN.

Nabout, N.A., 2015, 'A novel approach for bidding on keywords in newly set-up search advertising campaigns', European Journal of Marketing 49(5/6), 668-691. https:// doi.org/10.1108/EJM-08-2013-0424

Neethling, R., 2008, 'User profiles for preferences of search engine optimisation versus paid placement', Unpublished Master's Thesis, Cape Peninsula University of Technology, Cape Town.

Olbrich, R. \& Schultz, C.D., 2014 'Multichannel advertising: Does print advertising affect search engine advertising?', European Journal of Marketing 48(9/10), 1731-1756. https://doi.org/10.1108/EJM-10-2012-0569

Panda, T.K., 2013, 'Search engine marketing: Does the knowledge discovery process help Online retailers?', The IUP Journal of Knowledge Management XI(3), 56-66.

Pavel, K., Pauwels, K. \& Gupta, S., 2016, 'Do display ads influence search? Attribution and dynamics in online advertising', International Journal of Research in Marketing 33(3), 475-490. https://doi.org/10.1016/j.ijresmar.2015.09.007

Pfeifer, P.E., 2005, 'The optimal ratio of acquisition and retention costs', Journal of Targeting, Measurement and Analysis for Marketing 13(2), 179-188. https://doi. org/10.1057/palgrave.jt.5740142

PRN, 2015, 'fishbat COO Scott Darrohn explains 4 reasons why companies should combine PPC with SEO', PR Newswire, TRIBECA, NY 2015 /PRNewswire-iReach/

PRN, 2016, 'Caroff communications reveals 5 ways PPC and SEO are used to enhance each other', PRNewswire, San Diego.

Sullivan, D., 2016, The periodic table of SEO success factors, SearchEngineLand viewed 01 December 2016, from http://searchengineland.com/seotable/ download-periodic-table-of-seo

Weideman, M., 2009, Website visibility: The theory and practice of improving rankings, Chandos Publishers, Oxford.

Weideman, M., 2015, 'ETD visibility: A study on the exposure of Indian ETDs to the Google Scholar crawler', Proceedings of the 18th International Symposium on Theses and Dissertations, New Delhi, India, November 2015.

Yang, Y., Zhang, J., Qin, R., Li, J. \& Wang, F., 2012, 'A budget optimization framework for search advertisements across markets', IEEE Transaction on Systems, Man, and Cybernetics 42(5), 1141-1151. https://doi.org/10.1109/TSMCA.2011.2172418

Zuze, H. \& Weideman, M, 2013, 'Keyword stuffing and the big three search engines', Online Information Review 37(2), 268-286, viewed 11 December 2016, from http://www.emeraldinsight.com/doi/abs/10.1108/OIR-11-2011-0193 